AJST

journal.amca2012.org

\title{
Conversational cohesion in students' Whatsapp chat within online EFL learning
}

\author{
Naela Hidayatul Mukaromah ${ }^{{ }^{*}}$, Sri Wuli Fitriati ${ }^{1}$, and Zulfa Sakhiyya ${ }^{1}$ \\ ${ }^{1}$ Postgraduate Program, Universitas Negeri Semarang, Indonesia \\ *Corresponding author: naelamukaromah@gmail.com
}

KEYWORDS

Cohesion

Conversation

Online Learning

WhatsApp chat

\begin{abstract}
The pandemic of COVID-19 has shifted physical learning mode into online learning. The phenomena led communication technology to assist the implementation of online learning. For some reasons, WhatsApp Messenger becomes a commonly-used technology to discuss learning materials. However, the flow of students' conversation or discussion via WhatsApp chat rose a problem of text relation in creating meaningful conversation. The analysis of conversational cohesion, thus, needs to be taken into account. This study aims at analyzing conversational cohesion on students' written chat in WhatsApp group within online EFL learning in Indonesia. Two series of students' conversation in WhatsApp group became the research object. The study found that students' written chat applied all types of cohesive devices appropriately; either grammatical or lexical cohesion. Meanwhile, the distribution of appearance for each type differs one another. Reference obtains the most occurrence in the conversation while lexical cohesion is the most rarely applied. It is highly expected that future research may pay attention to the realization of students' conversational cohesion in any sorts of technologies as learning media for students in various educational levels or grades.
\end{abstract}

(c) The Author(s) 2022

\section{INTRODUCTION}

Since the last period of 2019, the whole world has been fighting hard to face COVID-19 pandemic which affected many aspects of life, one of which is education. The teaching and learning process in schools around the world is now established online because the direct physical interaction between people is extremely limited. Online learning turns to be something undeniable particularly in Indonesia. Data from Ministry of Education and Culture on June 6,2020 showed that there was a direct impact of the crisis on school closures. There were 646,192 schools which were closed during the pandemic. It also gave impact on the learning process undertaken by $3,147,870$ teachers and $62,561,660$ students over the country. Therefore, online learning in Indonesia becomes one of solutions for supporting the educational learning within the pandemic as well as the school closure in the purpose of reducing the transmission of the virus (Bank, 2020).

The existence of technology highly assist the implementation of online learning in this country. WhatsApp is one of the commonly-used technology which bridge communication between teachers and students in distant. The usability of WhatsApp Messenger as learning media within this pandemic obtained sufficient to good rate (Dhahir, 2020). There was $75 \%$ of the respondents use WhatsApp as learning media and only $25 \%$ use LMS (Susilowati \& Supriyatno, 2020). These phenomena showed that many teachers and students discuss the learning materials for each meeting via WhatsApp chat due to the high flexibility of WhatsApp for its users and the increase of students' motivation and enthusiasm within the online learning through WhatsApp (Djamdjuri \& Kamilah, 2020; Mulyono et al., 2021; Kholis et $\mathrm{al}, 2020)$.

The use of Whatsapp also happened to the implementation of online EFL learning in Indonesia. Although most classes are conducted online in live teaching learning process but some are undertaken through online discussion via written chat room using WhatsApp. WhatsApp group, particularly, becomes the most applicable media for conducting the meeting since it enables teachers and students to send, reply and comment ideas from and for all members of the group. Via WhatsApp chat room, the students are given several topics to present and discuss. One topic would be presented by one group for each meeting while other members of the class would respond to the group's explanation and there was the discussion ongoing. Any idea from students was conveyed in written form within specific time. However, the flow of discussion via written chat room rose problems. The issue comes up with how students pay attention to the relation of text in their written chat. In detail, it emerged some questions such as whether the students convey their ideas in good arrangement, whether all students really engage themselves on the discussion, whether the students' explanation is elaborated thoroughly via chat room, how the flow of discussion is during the meeting and how the learning process creates such meaningful discussion.

To identify whether a text, either written or spoken, is unified, connected, or related each other to create meaningful ideas, one should take cohesion into consideration. 
The notion of cohesion has long been regarded by some linguists. The grand theory which led cohesion as the essential element in creating meaningful text is Halliday \& Hasan (1976). They mentioned that cohesion is a tie bounding some words within text which makes a text contain such texture to be a meaningful unit of language. Since it deals with relations of meaning, they define the cohesion as more semantic concept instead of structural or syntactical. Some experts also mentioned other views of cohesion. Cohesion is an obvious relationship expressed through sentences (Widdowson, 1978). It is defined as a concept of how the components of the surface text-i.e the physical words we hear or see-are reciprocally connected within a sequence (De Beaugrade \& Dressler, 1981). It is also the component of a text (Moon, 2001) as well as the relation between either forms or meanings exist inside the text (Martin, 1992). Thus, cohesion is discretely seen as sorts of conjunctions between sentences. To sum up, cohesion refers to a relation of forms and meanings which are found in the surface of sentences and exist within a text so it can be obviously observed. Cohesion, as a component of text, is analyzed by its types of cohesive ties found in the relation of one sentence with another; either in written or spoken text, in paragraph or sort of conversation. There are some types of cohesion in terms of semantic and lexical level. Regarding semantic relation, there are conjunction, reference, and substitution (Halliday \& Hasan, 1976). Meanwhile, lexical relation deals with the view of cohesion in the surface level of the text. Each type has its own classification. Conjunction is divided into additive, adversative, causal and temporal relations, external and internal conjunction. Reference include personals, demonstratives, definite article and comparatives. Substitution deals with verbal, nominal or clausal substitute and ellipsis. The last part, lexical cohesion covers collocation, reiteration, synonym, superordinates and general word. .

The analysis of cohesion had been such concern by many researchers. Some identified cohesive devices in written and spoken text such as essay, formal writing, speech, novels, etc. Meanwhile, some identified cohesion in conversation. The examples include cohesion analysis in conversation. Following this, a particular term is created as conversational cohesion; cohesion found in conversation. There were still limited studies which had taken conversational cohesion into account. Cohesive devices have variations in some conversations in novel sea poppies (Antony, 2014). The analysis was briefly explained each conversation and the cohesive devices applied within it. Systemic cohesion in Facebook and Twitter for Indonesian user can be divided into structural (which is represented by the functions of conversation components, indentation, and vertical line) and textual cohesion, which is implemented in the form of mention and hashtag (Muttaqien, 2019). In this case, Facebook and Twitter shared similarities and difference in term of the implementation of cohesive markers. Further, cohesion is also found in Facebook timeline conversation (Muttaqien et al., 2019). Both grammatical and lexical types of cohesion could be found in Facebook. Nevertheless, their distributions were different from one another. The domination was taken over by grammatical cohesion by the huge existence of reference, ellipsis, and conjunction. Taking quite different setting of conversation, $\mathrm{co}^{-}$ hesion of students' conversation in the classroom can provide a special analysis (Muhammad, 2016). The study used recorded conversation as its data. The students were asked to choose some lists of topic for the content of their conversation. The research showed that students often applied grammatical and lexical cohesive devices but they did not know how to apply them appropriately within the conversation. Having similar case to this research, cohesive devices in students' designed-conversation was analyzed (Amiliani \& Gani, 2015). Three students were intentionally asked to do an informal conversation talking about certain topic given by the researcher. The study inferred that students had fairly good level of discourse competence so they were able to make utterances in the conversation cohesively.

Based on the previous studies, some of them focused on the analysis of cohesive devices in natural informal/casual conversation whereas some conducted research on designed formal conversation. There was no study discussing cohesion in natural formal conversation taking place in educational setting within written chat of WhatsApp group. Meanwhile, the implementation of online learning, moreover EFL learning, during the pandemic is commonly assisted with WhatsApp chat as its media. Hence, this study aims at analyzing conversational cohesion on students' written chat in WhatsApp group within online EFL learning in Indonesia. The students' chat was about a discussion of the learning material in the classroom. Hopefully, this research may give new understanding to students, teachers and educational practitioners about conversational cohesion in students' conversation. They may be aware of applying cohesive devices within their utterances. The findings of this study can also become a comprehensive concept for teachers to support students in building cohesion in all forms of text in whatsoever media, particularly in conversation through social media chat.

\section{METHOD}

This study applied descriptive qualitative research approach by focusing on classroom discourse analysis as the research design. The analysis of cohesion is one of the theoretical aspect covered in the classroom discourse analysis. There were 14 students in Pascasarjana UNNES which belong to one class namely Rombel 3 as the research subject. Meanwhile, two series of the students' conversation in their WhatsApp written chat of conversation was the unit of analysis which became research object for this study. The language that students used in the chat was English language. Further, the conversation refers to the discussion held by the students in talking about one topic of lecture they learn. The conversation in the WhatsApp chat group was naturally conducted by the students without any either instruction, interruption or manipulation from the researcher.

In collecting the data, I transcribed the students' written chat using facility to export chat in WhatsApp as one of the research tool. I was a complete-participant observer who became a fully embedded researcher and almost like a spy. Other students were not be aware that observation and research was being conducted. In other words, I engaged with the participants and partake in their learning activities. While the students were not realize that their learning process was recorded as my data. Then, I analyzed the data by designing a table of cohesion analysis which was developed from the theory of Halliday \& Hasan (1976). The table consists of types of cohesion and the example of each type from the data (of written chat). The result from table 
of analysis was further interpreted by reviewing and comparing other literature to gain findings and conclusion.

\section{RESULTS AND DISSCUSION}

The students' conversation within WhatsApp written chat was talking about several topics given by the lecturer as their learning material. It has particular structure that is regularly followed by all students. Those students were added into a WhatsApp Group (WAG) which enables them to actively engage with the discussion. Further, there was some small groups consisting of three students for having presentation in each session. In general, the structure of conversation was opening, material presentation, question and answer session, response and comments, closing. The opening would be done by the presentation group as well as presenting their materials. The presentation file was sent to the WAG while other students would read, learn and respond to the file. Following that, a Q \& A session was held by letting some students to ask question then replied by the member of presentation group. All students were also pleased to add answer or comments to the asked question. The discussion ran smoothly although not all students texted their comments yet they were actively following the discussion. After all questions were answered and there was no any additional response, the meeting would be closed by the presentation group.

Based on the data, students applied almost all types of cohesion appropriately. Only superordinate which belongs to lexical cohesion was not mentioned by the students in their written chat. The data analysis comprised the use of each type of cohesive markers found in students' chat that will be elaborated as the following explanation.

\subsection{Conjunction}

Relation of text is usually connected by conjunction. This is sort of simple way to bridge words, phrases and sentences. According to Halliday \& Hasan (1976) conjunction as one of cohesive ties is divided into four categories based on each function; additive, adversative, causal and temporal. Additive functions as adding some new information while adversative is mentioned to state the contrary thing which opposite the previous statement. Causal gives certain reasons and excuses why something happened and temporal focuses on the series of time. In analyzing conjunction, the focus was on individual utterances because it has nothing to do with the relation of one's utterance to other students' utterance. It only connects one word or sentence. The Table 1 shows the occurrence of conjunction applied by students within their written chat.

The table tells us that the most dominant conjunction used belongs to additive conjunction particularly the word 'and'. It indicates that in students intend to convey ideas as much as they have in their mind by frequently adding some important information. They need to elaborate and explain what they have already said to make other students really understand with their ideas. Therefore, students want to make sure that they speak up what they know completely by applying additive conjunction to bridge their sentences. The use of additive is exemplified in utterances below.

26/03/20 13.33 - S2 Teguh: Good afternoon guys, how are you today? I hope you guys are doing great and stay healthy in the age of Covid-19 virus. let's discuss about Pragmatics.

The phrases doing great and stay healthy are completing each other. 'stay healthy' is another phrase added to give another statement to 'doing great' since they have quite similar meaning. Thus, the word 'and' here functions as additive conjunction. However, there was a case when 'and' functions nor only as additive but also temporal.

26/03/20 14.43 - S2 Reza: I saw your slide and I found indexical. perhaps you know a little bit about that. But you did a great job brother.

Here, the students said that he saw the presentation slide then he found the word 'indexical'. The student could find the word 'indexical' after he read along the slides. It shows that the use of conjunction 'and' in this case has the same meaning with 'then'. Although it was a formal discussion, chat language is more flexible than formal writing. Further, a conversation realized in written chat rarely follows the grammar rules. Thus, the function of one conjunction may differ to one another as long as someone's idea is completely delivered and understood.

This finding of the use of 'and' in written chat is quite different with Amiliani \& Gani (2015) which discussed the application of conjunction 'and' in spoken conversation. Amiliani \& Gani (2015) mentioned that conjunction 'and' is

TABLE 1. The Occurrence of Conjunction

\begin{tabular}{|c|c|c|}
\hline CATEGORIES & CONJUNCTION & OCCURRENCE \\
\hline Additive & $\begin{array}{l}\text { And, or, else,so, and or, nor, by the way, in addition, besides, that is , i mean, in other } \\
\text { words, for instance, thus, on the other hand, in the sameway, like ..., unlike .... }\end{array}$ & $\begin{array}{l}\text { and }=40 \text { or }=15 \text { so }=9 \\
\text { in other words }=1 \\
\text { for example }=2 \\
\text { like }=6 \text { i mean }=1 \\
\text { that }=18\end{array}$ \\
\hline Adversative & $\begin{array}{l}\text { yet, though, only .... , but, however, nevertheless, despite this, in fact, actually, as a } \\
\text { matter of fact, however,instead, rather, on the contrary, at least, }\end{array}$ & $\begin{array}{l}\text { but }=5 \\
\text { only } \ldots=1\end{array}$ \\
\hline Causal & $\begin{array}{l}\text { hence, therefore, as a result, for this reason, in consequence, for this purpose, for, } \\
\text { because, on this basis, to this mind, then, otherwise, in this regard, aside from this, }\end{array}$ & because $=10$ \\
\hline Temporal & $\begin{array}{l}\text { then, next, after that, finally, first - then, at once, soon after a time, next time, on } \\
\text { another occasion, next day, meanwhile, until then, at this moment, up to now, from } \\
\text { now on, to sum up, briefly, in short, to resume }\end{array}$ & $\begin{array}{l}\text { then }=3 \\
\text { next }=1 \\
\text { now }=3 \\
\text { this time }=1\end{array}$ \\
\hline
\end{tabular}


used not only to connect students' ideas within their utterances but also to avoid hesitation of uttering sentences as spoken feature. Thus, conjunction 'and' is frequently applied to initiate one utterance and strengthen the previous ideas.

\subsection{Reference}

Reference is certain word which links to another word either the previous or following word, phrases or sentence. People commonly use reference to refer to particular thing so the word they mention has special meaning. For instance, the word "she" may refer to whoever female in this world, but the speaker intends someone in his mind when he mentioned 'she'. There are some types of reference; personal, demonstratives, definite articles and comparatives. Personal deals with reference to person or people and its possessiveness. Personal reference is also wellknown as personal pronoun. Demonstrative aims to point out something either physical or abstract thing. Definite article is also kind of reference since it must refer to particular object that has been mentioned by the speaker or writer. The last, comparatives explains similarity or difference between one object to the previous referred thing. The Table 2 is about the appearance of reference in students' written chat.

The table showed us that the use of personal reference obtained the most appearance in the students' chat particularly for first and second person pronouns. Similar with (Golfashani, 2003), it can be interpreted that conversation via written chat through WhatsApp group typically belongs to interactive discourse which engages multiple participants with active communication by sending textual messages to one another just like Facebook conversations. Further, in personal reference, there found the phrase 'Nuril's Brother' to refer to a student named Reza in the following conversation. Reza is well-known to have such good friendship with another student named Nuril, so Teguh mention Reza's name by reference 'Nuril's brother'. This shows a close relation among the students can create certain referential name pinned to particular student.

TABLE 2. The Appearance of Reference

\begin{tabular}{ll}
\hline Types of reference & The appearance of reference \\
\hline Personals & $\mathrm{I}=24 \mathrm{me}=7 \mathrm{my}=5$ \\
& You $=35$ your $=10$ \\
& They $=0$ them $=3$ themselves $=1$ \\
& We $=48$ our $=17$ us $=8$ \\
& He $=5$ him $=1$ his $=3$ \\
& She $=0$ her $=0$ \\
& It $=31$ its $=2$ \\
& S2 Teguh: thank you, Nuril's Brother $:)$ \\
& That $=5$ \\
Demonstratives & This $=10$ \\
& There $=11$ \\
& Here $=10$ \\
Now $=4$ them $=2$ \\
Definite articles
\end{tabular}

Some factors or situation also had such contribution in the existence of this kind of reference.

26/03/20 14.43 - S2 Reza: I saw your slide and I found indexical. perhaps you know a little bit about that. But you did a great job brother 26/03/20 14.44 - S2 Teguh: thank you, Nuril's Brother :)

Another phenomena is the use of 'then' as demonstrative reference while it refers to cataphoric reference. It is cataphora since the referent relates with things following the reference. In the following, Mbak Puput mentioned the word 'then' to refer to specific time after she already texted that chat. Since it refers to the following time or situation, it can be called as cataphoric reference.

26/03/20 14.04 - S2 Raka: by now, we are sorry because we got to close the question session while our team is about to figure them out. hang on your seat please. 26/03/20 14.05 - S2 Mbak Puput: Okay, Sir. Take your time then

The unique thing in WAG chat is that a user may forward other user's chat to refer their chat and give certain comment. The Figure 1 shows us how Mbak Puput refers her statement "And there is already a question from Mbak Amel' to Mbak Amel's chat of question. Then, Mbak Erlin wants to give additional statement by forwarding back Mbak Puput's chat. It means that the presentation group were still waiting for two more questions as well as suggestion or additional information by other students.

\subsection{Substitution}

Substitution is used when someone wants to apply another word to substitute his words/phrases. Sometimes, a person needs to remove his words/phrases by applying ellipsis or substitution with no substitute. There are certain words which can function as substitution. They are so do I, neither nor, if not, if so, also. The following utterances are the instances of substitution and ellipsis which showed us that sometimes the speakers wanted to avoid repetition and omit unnecessary phrases for efficiency like found in spoken discourse (Amiliani \& Gani, 2015).

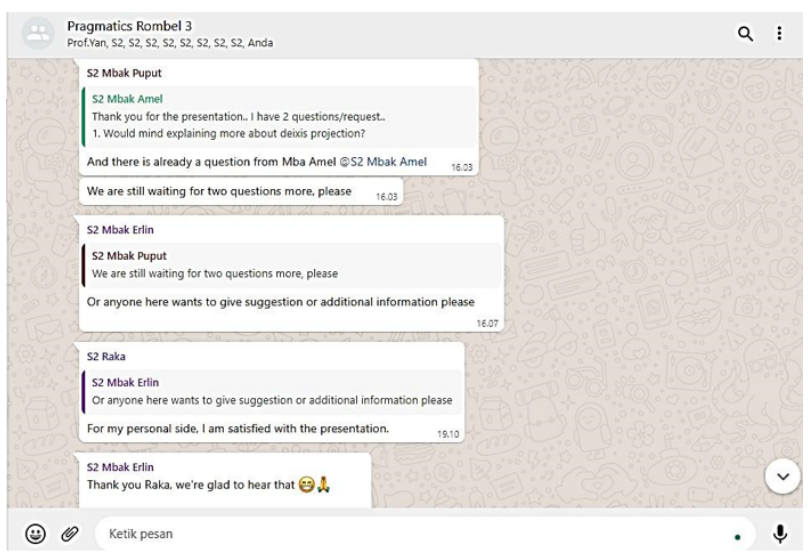

FIGURE 1. The display of WhatsApp group chat 
Prof Yan: We like to hear also from the other students

Prof. Yan said also since there were some students gave their comments, responses and opinions previously. However, other students were still quiet. Therefore, Prof. Yan invited other students to give their opinion too. The word 'also' substitute the meaning of other opinion too from the students.

03/04/20 21.30 - S2 Mbak Erlin: Exactly.. what do you think mba amel, can we use deixis to hide our message?

03/04/20 21.32 - S2 Mbak Amel: I think so.

The phrase 'I think so' means I think we can use deixis to hide our message. However, Mbak Amel used 'so' to simplify the conversation while the meaning can be understood by others.

26/03/20 14.55 - S2 Raka: Aight. Thought no more to discuss. so we would like to thank to you all guys for your participation and cooperation

Ellipsis is represented in the above utterance by Raka. He started his utterance by saying 'tought no more to discuss' without mentioning subject of that sentence. Other students whereas understood the meaning. Raka omitted subject I which refers to himself by applying ellipsis. The complete sentence would be 'I thought no more to discuss'.

\subsection{Lexical Cohesion}

Lexical cohesion is realized in other words which belongs to reiteration and collocation. Reiteration is classified into repetition, synonym, general word and superordinate. The function of reiteration is to strengthen the meaning of one's statement while collocation is two words which is usually used in group as one unity. The students' written chat almost realized these kinds of lexical cohesion except superordinate and general word. The instance of each kind is elaborated below.

The following utterance is repetition. First, Raka mentioned a term radical simplification and then, he used the word simplification and radical separately without removing its meaning

26/03/20 14.12 - S2 Raka: ... the next is a radical simplification from Semantics because in the simplification of semantic in giving meaning is getting radical or just straight to the point.

Synonym is found in the following utterance. The word analyze has synonym to interpret. It is kind of variation of word applied in someone's utterance.

26/03/20 14.23 - S2 Mbak Amel: When we try to analyze the context of a sentence, written form, is there any scientific way to validate to make sure that we interpret the context right?

Collocation is found in phrase 'questions and discussions'. It becomes one unity since when there is questions, it will be followed by discussion. The students commonly apply this collocation to make them familiar with the structure of the conversation.

\section{CONCLUSION}

Based on the findings, all types of cohesion is used in students' written chat. Nonetheless, the distribution for each type has such difference. The dominant cohesive markers used by students is reference since they frequently apply definite article to refer to previous word they already mentioned and personal pronoun to point out themselves or other students. The least use of cohesion type is lexical cohesion since there is only two instances of repetition, two instance of synonym and one collocation. However, the students have applied cohesion appropriately in their written chat. Although it is a lecture meeting via WAG chat, they really pay attention to the text relation so their conversation is easily understood and run smoothly. The instance of students' conversational cohesion within WAG written chat in this research can be a model depiction of the way teachers and students pay attention more to text relation. Hence, the English text created by both teachers and students approach good cohesive level so it is easily understood by other people. This study is still limited to a series of students' conversation in the form of WhatsApp written chat in natural setting. Also, the research subject is students in postgraduate level. Future research may pay attention on conversational cohesion of students' WhatsApp chat, not only in the written form but also in video, audio or voice note sent through WhatsApp group. Students from the lower level of education can also be the research subject so the next studies can have larger findings of students' cohesion in educational setting from students in all grades.

\section{References}

Bank, W. (2020). The Promise of Education in Indonesia.

Dhahir, D. F. (2020). The usability of whatsapp messenger as online teaching-learning media, J. Inf. Technol. Its Util., 3(2), 48. https://doi.org/10.30818/jitu.3.2.3629.

Susilawati, S., \& Supriyatno T. (2020). Online learning through whatsapp group in improving learning motivation in the era and post pandemic COVID -19, J. Pendidik. Teor. Penelitian, dan Pengemb., 5(6), 852. https: //10.17977/jptpp.v5i6.13670.

Djamdjuri, S. D. \& Kamilah, A. (2020). Whatsapp media in online learning during covid-19 pandemic, vol. 14(2), 6974.

Mulyono, H., Suryoputro, G., \& Jamil, S. R. (2021). The application of WhatsApp to support online learning during the COVID-19 pandemic in Indonesia," Heliyon, 7(8), e07853. https://10.1016/j.heliyon.2021.e07853.

Kholis, A., Nahdlatul, U. \& Yogyakarta, U. (2020). The use of whatsapp app in distance language learning, LET: Linguistics, Literature and English Teaching Journal, 10(2, 24- 43 .

Halliday, M. A. K., \& Hasan, R. (1976). Cohesion in English (Original work published 1976). Longman Group.

Widdowson, H. (1978). Teaching language as communication. Oxford University Press.

De Beaugrande, A. \& Dressler, W. (1981). Introduction to text linguistics. Longman. 
Hoey, M. (1991). Patterns of lexis in text. Oxford University Press.

Martin, J. (1992). English text: system and structure. John Benjamins Publishing Company.

Antony, F. (2021). Cohesion in conversation: a discourse stylistics approach on Amitav Gosh's Sea of Poppies, Int. J. Sci. Res., 3(10), 535-538, 2014, Accessed: Jun. 15. [Online]. Available: www.ijsr.net.

Muttaqien, M. Z., Ma'ruf, A., \& Hardjanto, T. D. (2019). Systemic cohesion in social media conversations: cases on Facebook and Twitter. Indones. J. Appl. Linguist., 9(2, 413-423. doi: https://10.17509/ijal.v9i2.20239.

Muttaqien, M. Z., Ma'ruf, A., \& Hardjanto, T. D. (2019). Cohesive markers in social media discourse: a case in Indonesian facebook conversations. Linguist. Indones., 37(2), 185-201. Accessed: Jun. 09, 2021. [Online].
Available: https://www.researchgate.net/publication /336072821_COHESIVE_MARKERS_IN_SOCIAL_M EDIA_DISCOURSE_CASE_IN_INDONESIAN_FACEB OOK_CONVERSATIONS.

Muhammad, H. A. (2016). Cohesion in students' conversation.

Amiliani, C., \& Gani, A. (2015). Strategic and discourse competence; a case of English foreign language students in graduate program. In $1^{\text {st }}$ English Language and Literature International Conference (ELLiC), pp. 302-308, https://jurnal.unimus.ac.id/index.php/ELLIC/articl e/view/2496.

Golfashani, N. (2003). Understanding reliability and validity in qualitative research, Qual. Rep., 8(4), 597-607 [Online]. Available: http://nsuworks.nova.edu/tqr\%0Aht tp://nsuworks.nova.edu/tqr/vol8/iss4/6\%0Ahttps: //nsuworks.nova.edu/tqr/vol8/iss4/6. 